\title{
El comercio de barrio como espacio de sociabilidad en contextos locales de migración
}

\author{
Paloma Gómez Crespo
}

Universidad Autónoma de Madrid, Madrid, España. Email: mariapaloma.gomez@uam.es

Resumen: Este artículo aborda el carácter clave del comercio de barrio como espacio para la sociabilidad en contextos locales de migración, centrándose en tres planteamientos que contribuyen a analizar tanto situaciones de convivencia armoniosa como de conflictividad entre vecinos de distintos orígenes etnoculturales: 1) la vinculación entre el comercio como elemento visibilizador de expresiones identitarias y la construcción culturalista del conflicto; 2) cómo se articula el comercio con otros espacios de sociabilidad; y 3) la multiplicidad de espacios de interacción que ofrece la actividad comercial.

Palabras clave: sociabilidad, migración, comercio, convivencia, conflicto

\section{Neighborhood commerce as space for sociability in local contexts of migration}

\begin{abstract}
This paper deals with neighborhood commerce as a key sphere for sociability in migration local contexts. It is focused in three questions that contribute to the analysis of harmonious as well as conflicting relationships between neighbors of different ethnocultural origins: 1 ) the link between commerce as a place where etnocultural identity is expresed and culturalist construction of conflict; 2) how commerce articulates with others spaces of sociability; and 3) the multiplicity of spaces that commercial activity offers for interaction.
\end{abstract}

Key words: sociability, migration, commerce, living together, conflict.

\section{O comércio de bairro como espaço de sociabilidade em contextos locais de migração}

Resumo: Este artigo discute o caráter-chave do comércio local como espaço para a sociabilidade em contextos locais de migração, com foco em três abordagens que ajudam a analisar as duas situações como convivência harmoniosa e conflitividade entre vizinhos de diferente origem étnica e cultural: 1) a ligação entre o comércio como elemento visibilizador de expressões de identidade e construção culturalista do conflito; 2) como o comércio se articula com outros espaços de sociabilidade; e 3) a multiplicidade de espaços de interação oferecidos pela atividade comercial.

Palavras-chave: sociabilidade, migração, comércio, convivência, conflito 
La crisis que azota a España en los últimos años está haciendo que despierte de su sueño de país del norte desarrollado para volver a su caracterización como país del sur, donde la emigración vuelve a colarse como salida al desempleo. Pero ello no significa que España, de repente, haya dejado de ser receptora de inmigración: aunque se observan flujos de retorno y nuevas migraciones de quienes llegaron cuando la situación era de bonanza económica, la realidad es que los barrios de ciudades como Madrid ya no se entienden sin la presencia de personas procedentes de otros orígenes nacionales y etnoculturales.

Estamos ante un nuevo escenario que amenaza los avances en materia de integración, convivencia y ciudadanía alcanzados hasta el inicio de la segunda década del 2000. De momento, hemos asistido al arrinconamiento del último Plan Estratégico de Ciudadanía e Integración ${ }^{1}$, a la retirada de la tarjeta sanitaria a los inmigrantes en situación irregular, a la desaparición de servicios municipales que trabajaban a pie de calle para favorecer la convivencia intercultural ${ }^{2}$, etc. En este nuevo escenario, donde en España se sobrepasan los 6 millones de personas desempleadas, donde los servicios sociales, sanitarios y educativos se recortan, mientras las clases medias y populares ven empeorar sus condiciones de vida, surge el interrogante de cómo pueda repercutir todo esto en la convivencia en los barrios y cómo trabajar para favorecerla. ¿Se producirán o se están produciendo en España reacciones xenófobas que toman a la población inmigrada de origen extranjero como chivo expiatorio como ha sucedido en otros lugares como Grecia, otro país del sur que soñó con ser norte? Por el momento, en el territorio español esto no ha sucedido, al menos no de manera generalizada, pero las condiciones de vida de amplios sectores de la población, tanto autóctona como inmigrante, empeoran abonando las ideas preexistentes de “competencia” por los recursos escasos, de preeminencia del autóctono frente al extranjero, algo fácilmente aprovechable por discursos políticos populistas que pueden dar al traste con todo lo avanzado en materia de convivencia y construcción de la comunidad ${ }^{3}$, no sólo por planes, programas y acciones de instituciones públicas y no gubernamentales, sino por los propios vecinos de los barrios.

Este artículo se enmarca dentro de una corriente de Antropología de Orientación Pública comprometida con la sociedad, con el propósito de hacer aportaciones que sirvan para gestionar mejor los conflictos, y reforzar o impulsar la convivencia y la cohesión social en los barrios multiétnicos. Para ello partimos, en primer lugar, de un enfoque interculturalista (Giménez 2009a) que incide en la conexión entre desarrollo humano, cultura y derechos humanos, en la relación entre estado de bienestar y discriminación étnica y en la socialización de la gestión pública a través de los principios fundamentales de igualdad y no discriminación etnoracial, respeto y derecho a la diferencia etnocultural, y de interacción positiva. En segundo lugar, analizamos la sociabilidad desde una operacionalización del concepto en dimensiones e indicadores que permiten diagnosticar distintas situaciones y sus tendencias hacia la convivencia, la coexistencia o la hostilidad (Giménez 2009b). Y en tercer lugar, abordamos el análisis de la 
conflictividad desde un planteamiento multifactorial que tiene en cuenta la interconexión entre factores culturales, situacionales y personales con el fin de superar construcciones culturalistas del conflicto (Giménez 2002). Todos estos enfoques han sido incorporados en el Instituto Universitario de Investigación sobre Migraciones, Etnicidad y Desarrollo Social (IMEDES) tanto en el ámbito de la investigación como de la intervención, contribuyendo a adaptar los planteamientos de la intervención comunitaria a barrios multiculturales con el fin de promover la convivencia en los contextos locales ${ }^{4}$.

A lo largo de estas experiencias ha quedado claro que un ámbito clave para el trabajo de lo comunitario es el comercio de barrio, dado su papel en la vida vecinal, y al que, sin embargo, no se le ha prestado toda la atención que debiera. Poco a poco empiezan a aflorar estudios y experiencias de intervención que lo incorporan ${ }^{5}$, pues es de referencia obligada para fundamentar y construir la "comunidad". El espacio comercial es clave para abordar la convivencia en cualquier barrio, por lo que también es absolutamente relevante en el caso de los contextos que protagonizan procesos de diversificación sociocultural: 1) porque es "uno de los elementos regulatorios de las relaciones entre lo público y lo privado” (Monnet 1996: 12); 2) por la prolongación de su influencia más allá del perímetro del establecimiento hasta articularse con el resto de los espacios de sociabilidad vecinal; 3) porque es uno de los espacios donde más se evidencia y refleja el asentamiento de la población migrante en las sociedades receptoras, donde se visibilizan nuevas identidades propiciándose el reconocimiento entre los que se perciben como "otros"; 4) porque la ocupación del espacio comercial por parte de los nuevos vecinos implica interacción, ya sea conflictiva, armoniosa o indiferente, entre individuos y grupos diversos y, por lo tanto, un espacio ineludible donde se juega la convivencia.

Los establecimientos comerciales, donde incluimos la oferta de bienes y servicios, así como bares, restaurantes, peluquerías, etc., constituyen un espacio clave para la vida vecinal en los barrios, tanto por lo que en ellos acontece, como por su articulación con otros espacios donde se desarrolla la vida cotidiana del barrio. Son pues espacios fundamentales para la sociabilidad y, por lo tanto, de referencia obligada para fundamentar y construir la comunidad y la convivencia. Y lo son porque en y en torno a ellos se produce interacción entre vecinos en los distintos papeles que pueden adoptar con respecto al comercio (clientes, comerciantes, dependientes, vecinos), con distintas intensidades, contenidos y modalidades: desde la convivencia armoniosa al conflicto abierto. Por otra parte, el ámbito comercial desempeña también un papel clave en la reproducción de la(s) cultura(s) de los vecinos a través de los productos y servicios que ofrece y la manera de hacerlo: desde una determinada forma de cortar la carne a un peinado en la peluquería. La interconexión de este doble papel adquiere, como veremos, una relevancia especial en el caso de contextos multiculturales, en cuya configuración tiene un papel protagonista (aunque no exclusivo) el fenómeno migratorio. 
Podemos concretar este doble papel en seis dimensiones que nos ayudan a entender cómo contribuye el comercio a la sociabilidad en los barrios (Gómez Crespo 1994: 413) ${ }^{6}$ : a) como lugar de encuentro y tertulia, b) receptor y difusor de información, c) canalizador de favores y ayuda, d) participante y colaborador en acontecimientos de interés para la comunidad, e) como espacio donde se visibiliza la identidad cultural y pertenencia al grupo(s), y como espacio para la recreación identitaria. En definitiva, como señalan Zegri, Navarro y Aramburu (2009: 38) "los comercios barriales y de proximidad tienen un claro papel en la vertebración comunitaria, pues son nodos que entrelazan muchas personas diversas que residen en el mismo territorio. Asimismo, son escenarios donde se generan (y reproducen) discursos, juicios y prejuicios sobre el territorio y los grupos que lo habitan. El pequeño y mediano comercio de barrio tiene, en definitiva, una importancia significativa en el desarrollo de actitudes de acogida o de rechazo hacia los nuevos vecinos”.

Aunque en este artículo no se podrá abordar ni profundizar en cada una de estas dimensiones, si se tendrá en cuenta su interconexión para reflejar el papel de la actividad comercial en la sociabilidad y, por lo tanto, en la convivencia, entendiendo ésta no como ausencia de conflictos sino como una situación en la que existen mecanismos para gestionarlo positivamente (Giménez 2005: 15). De este modo, enfatizaremos la necesidad de analizar lo que acontece en este espacio de interacción y de relación vecinal de cara a una intervención comunitaria que pretenda fomentar la convivencia intercultural.

Para tratar estas cuestiones se aborda el comercio de barrio como espacio de sociabilidad a partir de distintas investigaciones llevadas a cabo por la autora en torno al ámbito comercial desde principios de la década de 1990. En las páginas que siguen se reflexiona sobre el papel del comercio en la sociabilidad a través de varios planteamientos que venimos aplicando y desarrollando dentro del Proyecto I+D sobre "Conflictividad y migración en contextos locales. Una aproximación teórico-práctica a la convivencia y la mediación" $: 1$ ) la vinculación entre el comercio como elemento visibilizador de expresiones identitarias y la construcción culturalista del conflicto; 2) cómo se articula el comercio con otros espacios de sociabilidad y 3) la multiplicidad de espacios de interacción que ofrece la actividad comercial frente a la idea de guetización.

\section{Expresión identitaria y construcción culturalista del conflicto}

En primer lugar, me voy a referir a la visibilización de la expresión identitaria que conllevan los establecimientos comerciarles y, por lo tanto, el papel que esto tiene en las relaciones entre grupos de distintos orígenes en contextos migratorios y, de manera muy especial, en la construcción por parte de vecinos autóctonos de discursos de la "invasión”. Conviene evitar 
concluir que la raíz del conflicto esté en esa visibilización y, por lo tanto, su “solución” en la "invisibilización”, pues “sólo podemos hablar de verdadera convivencia cuando, en una sociedad, la presencia de los otros, de quienes son o se reconocen como diferentes mutua o unilateralmente, y la visibilización de sus identidades a través de sus prácticas (artísticas, alimentarias, comerciales, indumentarias, deportivas, de ocio, de comunicación, religiosas, etc.), no supongan una fuente de conflictos insuperables. [...] Una convivencia alcanzada al precio de la eliminación o ocultamiento de lo diverso, de lo diferente, de los otros, ya sea desde un punto de vista etnocultural, de edad, género o clase o ideológico, no es convivencia" (Gómez y Martínez 2013), sino mera exclusión.

En el trabajo de campo realizado dentro del Proyecto I+D ya mencionado, se observaron situaciones y se recogieron testimonios que remiten a dicha visibilización. Ofrecemos algunos de ellos, recogidos en 2012 en un bar del barrio madrileño de Almenara, en el distrito de Tetuán ${ }^{8}$ :

“[...] vienen como escondiéndose. Y la inmigración, trato que tienen con nosotros, pues ninguno." "Es que son ellos los que no quieren integrarse, los españoles somos gente afable, y somos hospitalarios...” (Dueña española del bar).

"Los bares que cogían los latinoamericanos, porque los dejaban los españoles, por ejemplo. Pues eran un gueto [...]; se metían allí, abrían el bar, ique no entienden de nada! Y claro, han ido al fracaso porque no saben. Saber no es simplemente poner un café y poner un vaso de vino. Hay que saber dónde se compra el vino, qué clase de vino toma el cliente. ¿Qué ha pasado? Que ellos [los inmigrantes] se han puesto a hacer sus comidas, querer venderlas a nosotros [los españoles]. Yo vengo aquí, y me tomo mi paella, mis boquerones en vinagre, madrileño o español. Pero no, ellos te ponen unas cosas que tú... y no saben. Son muy sucios, muy sucios, hablo en la cuestión de los bares. Ponen música, aquí no está permitido, aquí no puedes poner tú ahora música alta y estar la gente bailando. Entonces esta gente, claro, abría los bares, y era pues para ellos solos, porque se ponían a bailar en las barras, se ponían a bailar, pues en cualquier rinconcito. El vecino [español] no entra, yo estoy en mi barrio, pero yo allí no puedo entrar porque eso es un gueto, y luego muy mala bebida, claro.” (Cliente español del bar).

En 2005, el representante de una asociación de comerciantes de Madrid aseguraba ${ }^{9}$ :

Los comercios creados o que han pasado a estar regentados por inmigrantes, "en la mayoría de los casos, son comercios que dirigen para la población de inmigrantes, con lo cual este es el fenómeno de llegar a producirse esos guetos, esas áreas cerradas donde se venden productos para ellos, los restaurantes para ellos, la comida para ellos, los bares para ellos”. 
Estos discursos, así como las actitudes y miedos que expresan, son habituales en contextos locales que han protagonizado un asentamiento acelerado y voluminoso de población inmigrante. Así en Zegri et al (2009: 40) se recoge entre las preocupaciones de los comerciantes "de toda la vida" del barrio de Poble Sec de Barcelona "la guetificación de sus actividades comerciales [de los inmigrantes] que favorecerían las relaciones monoculturales, la ocupación incívica del espacio público por parte de la clientela de bares y restaurantes, su oferta comercial homogénea o su imagen cutre”.

Esta tendencia al repliegue hacia el interior de la propia comunidad implicaría, según este tipo de testimonios, que los inmigrantes frecuentan poco los establecimientos de los autóctonos dando pie a "reforzar" la idea de que son "ellos" los que se aíslan, los que no se quieren integrar. Ante esto hay que señalar dos cuestiones: en primer lugar, que la población inmigrante realiza sus compras cotidianas en los mismos lugares donde lo hace habitualmente la población autóctona, sobre todo, en cadenas de supermercados que ofrecen precios baratos como señalan distintos estudios y encuestas $^{10}$, lo cual significa que se dan múltiples situaciones en las que interaccionan con los autóctonos alejándose completamente de la idea de autoaislamiento. Y, en segundo lugar, que en aquellos locales de autóctonos con poca o nula presencia de inmigrantes habrá que tener en cuenta distintos factores que lo expliquen, entre ellos la acogida que tengan por parte de quienes los atienden o los frecuentan. Baste como ejemplo, la experiencia relatada por uno de los investigadores que recogió el testimonio del bar de Almenara al que nos hemos referido. Eduardo es angoleño y en una de sus sesiones de observación participante en el bar vivió la siguiente situación: “[...] me quedé un poco intrigado con un cliente que no me conocía, pero cuando me vio y me dice ¿chaval has visto lo que uno de tus paisanos hizo el otro día a nuestra princesa Letizia?, pues yo ignoraba el asunto y [la dueña del bar] me aclara un poco sobre el tema porque yo estaba anonadado. Resulta que en la recepción del Cuerpo Diplomático, en el Palacio Real (el día 25 de enero), el representante de El Congo retiró la mano a Doña Letizia poco después de tendérsela y antes de que ella pudiera saludarle. Tras la aclaración de [la dueña], me quedo sin saber decir nada y me quedé con esta sensación de siempre, que a los africanos muchos nos ven como si fuéramos todos del mismo país (más o menos como si África fuera un país y no un continente con varios países, diferentes grupos étnicos, diferentes religiones...). Pero busco no darle importancia al tema, me limito a decir al señor que no me había percatado de lo sucedido”.

La idea del gueto o, simplemente, ver como amenaza para la integración y la convivencia los establecimientos que, por su oferta, son frecuentados sólo por inmigrantes de determinados colectivos también la encontramos en profesionales especializados en el fomento de la convivencia intercultural que, aunque de manera bienintencionada, expresan argumentos que contribuyen a la estigmatización de este tipo de actividades ${ }^{11}$ que, sin embargo, desempeñan exactamente el mismo papel que los establecimientos autóctonos en cuanto a la expresión identitaria se refiere, si bien su 
papel es de especial relevancia porque contribuye a combatir el desarraigo de personas desplazadas de su entorno sociocultural. Una mediadora explicaba en $2005^{12}$ el proceso de sustitución de establecimientos comerciales regentados por autóctonos por otros regentados por inmigrantes en un distrito del sur de Madrid, con la consiguiente pérdida de referentes que dicho cierre tiene para la población autóctona envejecida de esa zona, y argumentaba lo siguiente:

"Un error es que, por ejemplo, un bar tradicional que pasa a ser regentado por una persona de origen dominicano deje de ser el bar tradicional que era, el bar de referencia de los vecinos/as de la zona, para convertirse en un bar dirigido especial y específicamente a la población de una determinada zona o país, lo que genera una dinámica de desvinculación entre los vecinos autóctonos, ya que se convierte en el bar de los dominicanos, lo que cambia totalmente la relación [...]. En muchas ocasiones estos comercios no se adecuan a que hay que prestar el mismo servicio tanto a los vecinos autóctonos como a los nuevos vecinos. Se genera cierta segregación ya que los vecinos/as ya no entran a ese bar porque es de los dominicanos.

Aunque bienintencionada, esta argumentación cae en la misma idea que se lee entre líneas en el primer testimonio recogido: la integración y la convivencia "se produce" si los inmigrantes se asimilan y "respetan" la hegemonía de los usos y costumbres de los vecinos autóctonos. Para el vecino que frecuenta el bar de Almenara, los inmigrantes que abren un bar y ofrecen sus comidas y bebidas típicas no pueden pretender que los españoles acudan a él, lo mismo que plantea la mediadora, y ambos concluyen, aunque con distintas intencionalidades, que el resultado de ofrecer sus productos es la "autosegregación”. Ambos coinciden en lo mismo: por un lado, negar el derecho a la propia expresión identitaria en favor de la hegemónica ${ }^{13}$ y, por otro, cargar toda la responsabilidad sobre el inmigrante, obviando que es el autóctono el que renuncia a entrar en esos bares porque los siente no sólo como extraños sino también como amenazantes. Por otra parte, no se aborda la situación contraria: que los establecimientos autóctonos incorporen productos y servicios al gusto de los extranjeros para que no sean "guetos" autóctonos ${ }^{14}$.

Estamos ante actitudes que se repiten en barrios sujetos a procesos de cambio socioeconómico previos al asentamiento de vecinos extranjeros (Gómez y Martínez 2012: 124), que suelen reflejarse, por un lado, en la perdida de población autóctona joven que se desplaza a otros lugares y en la desaparición de establecimientos tradicionales autóctonos por falta de relevo generacional y suficiente clientela ${ }^{15}$. Tanto en las viviendas como en los locales que quedan disponibles, los nuevos vecinos extranjeros abren sus negocios convirtiéndose a los ojos de los autóctonos no sólo en la imagen del cambio experimentado, sino también, en los únicos responsables del mismo, obviando que con su asentamiento revitalizan el barrio. Por ejemplo, Aramburu (2000: 293) señala para Ciutat Vella: "Paradójicamente, la apertura de pequeños comercios familiares servía para visualizar la 
crisis del pequeño comercio familiar. Esta dualidad, que aplica una lógica a los comercios inmigrantes y otra diferente a los comercios autóctonos y que ve en el apogeo de los primeros la decadencia de los últimos, se encuentra generalizada entre los comerciantes del distrito y sus representantes”. Pero, además, su presencia se percibe como una amenaza a la identidad de los vecinos autóctonos, pues como recoge también Aramburu (2000: 296 y 173), “[los inmigrantes, a ojos de los autóctonos] descaracterizan la identidad cultural de nuestro comercio[...]” pues “para los vecinos y vecinas de toda la vida la imagen de cerrazón y preservación cultural a ultranza adquiere una connotación más amenazadora o potencialmente hostil”.

En torno a esto se elaboran, incluso, discursos con los que “justificar” ese rechazo a los establecimientos a los que los autóctonos marcan "étnicamente”, olvidándose de que los suyos no son etnoculturalmente "neutros”. Por ejemplo, la dueña del bar de Almenara decía:

“aquí ha habido un vecino, que por la zona de Cuatro Caminos fue a un bar, no sé si era de sudamericanos, y no le atendieron, le dijeron que allí no. Le echaron, ¡le echaron! Dijo: ¡vamos, será posible! Mi hija, concretamente, no sé qué fue a hacer por allí, necesitaba cambio para el parquímetro, y el primer bar que encuentra, era también sudamericano, y ¡no! De malas maneras. ¿Tú te crees?, que vienen aquí, que le doy cambio a todo el mundo. Fíjate, es que vamos.... Es que esas cosas te dan rabia... Te tratan encima como si fueras, ¿sabes? Los mayores racistas son ellos, [...] porque los españoles no somos así, tú eres extranjero, te comportas como una persona, y para mí eres, vamos, de la familia, de mi casa, y de mi España. Y así somos los españoles ¡eh!, pero si no te comportas, son ellos los más racistas. Y los gitanos, más racistas, los moros igual.”

Este tipo de "leyendas" las hemos encontrado en otros estudios, por ejemplo, en el realizado en Torrejón de Ardoz en 2005 ${ }^{16}$, donde también los vecinos aseguraban que los “blancos” tenían prohibida la entrada en un bar de nigerianos, pero la indagación hecha por los investigadores concluyó que era un rumor que había ido creciendo a partir de una disputa puntual hasta convertirse en algo real para los vecinos autóctonos de Torrejón. En cuanto al incidente de la petición de cambio para el parquímetro, es un ejemplo de construcción cultural del conflicto, puesto que son muchísimos los comerciantes autóctonos de Madrid que se niegan a facilitar cambio, como expresan los carteles que cuelgan a la entrada de sus establecimientos.

Por lo tanto, una segunda idea fuerza, conectada con la anterior, es la que se refiere a la tendencia a construir "culturalmente” el conflicto cuando las partes en confrontación se reconocen mutua o unilateralmente como distintas por sus orígenes nacionales o etnoculturales ${ }^{17}$. Cuando esto sucede “el cómo, el dónde, el cuándo y el quién [relevantes para el análisis de la disputa] tienden a percibirse fundamentalmente en términos de lo que podríamos llamar una competencia identitaria que se refleja en la ocupa- 
ción, uso y apropiación del espacio público [en este caso también comercial]”. El cómo y el dónde remiten a la idea de invasión que sienten los autóctonos ante la apertura de establecimientos comerciales "de extranjeros" cuando cierran los de "toda la vida", sobre todo en aquellos barrios donde también se ha producido un fenómeno similar en las viviendas (el fenómeno al que se refiere el testimonio de la mediadora recogido más arriba). La evidencia de que una buena parte de esos establecimientos ofrecen productos y servicios al gusto de los nuevos vecinos suele interpretarse por parte de parte de vecinos autóctonos como prueba de la poca voluntad de los inmigrantes de "integrarse". Esto se completa con la idea de que esa ocupación del espacio comercial implica la expulsión del autóctono de un espacio que considera como propio o, al menos, en el que "debería tener preferencia” como vecino de toda la vida y "español”.

En el cuándo apreciamos una prolongación de lo anterior, pues también se percibe como "invasión” que los usos del tiempo y lo que es apropiado o no hacer en cada momento difiera para vecinos españoles y de origen extranjero. Pero, en última instancia, lo que marca la construcción cultural del conflicto es el "quién": "quién realiza esas prácticas que se viven como molestas y quién las siente y denuncia como molestas” (Martínez y Gómez 2012). O como lo expresan Zegri et al (2009: 41) refiriéndose a la situación de conflicto entre vecinos autóctonos y clientes de bares dominicanos en Poble Sec y el ruido que hacen por la noche: “[...] lo que genera el conflicto no es tanto la acción o el comportamiento de una de las partes sino su identidad. Lo que molesta del otro no es lo que él hace sino lo que es, y sobre todo que esté aquí”.

Todo esto implica que parte de la población tendería a autoexcluirse o evitar ciertos espacios, entre ellos establecimientos comerciales porque no los siente como propios. En otro lugar (Martínez y Gómez 2012) señalábamos que "esto contribuye a una sociabilidad basada en la coexistencia, que en ocasiones deriva hacia hostilidad"; sin embargo, conviene matizar esto tomando como referencia la primera idea que apuntábamos en cuanto a que convivencia es incompatible con exclusión. La clave aquí no es tanto que los establecimientos comerciales que, por los productos y servicios que ofrecen, sean sólo o fundamentalmente frecuentados por personas de determinados colectivos (ya sean autóctonos, de origen extranjero o de distintos grupos étnicos), sino que este hecho se perciba como un problema o amenaza y no, como lo que es: un espacio más de sociabilidad.

\section{El comercio de barrio y la articulación de espacios de sociabilidad}

Un segundo aspecto relevante para analizar el papel que el comercio desempeña en la sociabilidad, tanto desde el punto de vista de la convivencia armoniosa como de las situaciones conflictivas que de hecho se producen en torno al mismo, es la articulación del espacio comercial con los 
otros espacios donde se desarrolla la vida vecinal. En Gómez y Martínez (2012 a: 131) señalábamos: "el papel del comercio en la vida vecinal no se agota en lo que sucede "de puertas para adentro", sino que tiene otra vertiente de puertas para afuera. Estos establecimientos contribuyen a configurar el paisaje urbano, son puntos de referencia para los vecinos, refuerzan el sentimiento de pertenencia al barrio, de apropiación y reconocimiento del espacio como propio. La presencia de comercio crea rutas en los barrios por las que transitan los vecinos, permitiendo el encuentro más allá del interior de los locales, y, por lo tanto, la interacción: en este ir y venir también se juega la convivencia”. Pero esta articulación de espacios también tiene otra cara de la moneda: "cuando este solapamiento del espacio comercial y público, esta capacidad de atracción puede dar lugar a problemas de ruido, suciedad, olores, problemas de aparcamiento, etc. que los vecinos perciben y viven como una ocupación indeseada y molesta de un espacio que consideran como propio (por la repercusión que pueda tener en el espacio privado) o de todos (impacto en el espacio público)” (Ibid).

Lo que hemos podido apreciar en nuestra investigación es que la base de esas situaciones conflictivas -aunque tiendan a construirse culturalistamente- suele estar en el solapamiento de los espacios y, por lo tanto, en la colisión de las normas de convivencia que son aceptables para cada uno de ellos. Veamos algunos ejemplos.

Las quejas de las personas que habitan en los mismos inmuebles o aquellos cercanos a los establecimientos donde se llevan a cabo actividades que generan ruidos, desperdicios y olores, bien directamente o bien indirectamente por el ir y venir de su clientela, expresan uno de los tipos de situaciones conflictivas más habituales fruto del solapamiento entre espacios, en este caso el comercial, el residencial y el público, con distintas normas y valores asociados. Puede ser que el tiempo de descanso que se espera a ciertas horas en el espacio privado de las viviendas colisione con el tiempo de ocio que constituye la base de la actividad económica de establecimientos como bares, restaurantes, discotecas u otras actividades, así como con el uso del espacio público para actividades de esparcimiento (como el "botellón", pero también las terrazas de los bares). Pero la forma en que esto se percibe y vive por parte del vecindario y se afronta por parte de las autoridades puede no ser igual en función de quiénes sean los protagonistas de estas situaciones y del contexto urbano donde se producen. Algunos ejemplos recogidos en distintas investigaciones ilustran esta dinámica.

El dueño bangladeshí de un locutorio en el barrio de Acacias (distrito de Arganzuela), explicaba en 2005 que, al poco de abrir su negocio, tuvo un problema con los vecinos debido al cartel que puso en la calle (un caballete a dos aguas donde anunciaba su establecimiento). Un día apareció la policía municipal diciendo que debía retirar el cartel porque se habían quejado los vecinos. El comerciante explica que lo quitó, aunque nunca entendió por qué molestaba. En otra ocasión la presidenta de la comunidad de 
vecinos donde está su local le preguntó si no le importaría no dejar entrar público en el locutorio a partir de las once de la noche, por el ruido que se producía. Este hombre cuenta que desde entonces sólo deja entrar si hay alguien que necesita hacer una llamada importante, pero cierra la puerta; también asegura que si le dicen algo así, colabora, pero no si los vecinos hubieran tenido intención de molestar. Sin embargo, completa su relato asegurando que otros compatriotas suyos no han recibido apoyo por parte de sus vecinos porque no querían negocios de este tipo en los bajos de sus edificios y él mismo tuvo ocasión de experimentar este rechazo cuando buscaba local para su locutorio en Canillejas: cuando el dueño le preguntó qué negocio iba a abrir y le respondió que un locutorio, le explicó que los vecinos querían que se pusiera cualquier negocio menos un locutorio, porque de estos establecimientos entra y sale mucha gente. Es el mismo argumento que nos ofrecían responsables en materia de comercio del Ayuntamiento de Madrid también en 2005: los locutorios “a veces generan rechazo en los vecinos porque son tremendamente ruidosos [...] y los vecinos no pueden dormir los fines de semana. Son actividades que concentran a mucha gente en la calle, hablan muy fuerte, probablemente tienen otros hábitos; lo mismo con los bares de copas... policía, disparos... eso genera un rechazo al residente nacional... y la mente humana extrapola y dice es que son...”.

Los otros focos de disputa suelen ser los bares. En un estudio llevado a cabo en $2003^{18}$, Nina, una mujer polaca que había abierto un bar en Alcalá de Henares un año antes, relataba distintas situaciones conflictivas con sus vecinos:

“el día [de la] inauguración me han denunciado, el primer día, porque las mesas las he puesto [en la calle]. [...] La gente [que fue a la inauguración] ha cogido mesas y se ha puesto como quería [en la calle]. Es culpa mía que no me fijo, bueno no tenía idea de que lo tengo que poner de otra forma. En Polonia, si tú tienes una fiesta en casa y haces demasiado ruido, te viene el vecino a llamarte y te dice: bájate un poco la música porque me molesta. Y si tú bajas, bien, y, si no bajas, puede llamar a la policía. Y aquí llaman a la policía directamente. [...] El día de mi cumpleaños [un martes] han venido aquí 20 personas, mis amigos, $\mathrm{y}$ en un momento me han cantado el cumpleaños feliz en polaco, pues imagínate las diez menos cuarto [de la noche], pues a las diez menos cuarto ha venido la policía. Ellos me han dicho que no pasa nada, que por la hora no pasa nada, pero que si algún vecino llamaba, pues tenían que venir.” En otra ocasión el motivo de disputa fue el humo de la gente que fumaba en la terraza del bar, pues la vecina de la primera planta le dijo “iquita la mesa de aquí, porque me molesta el humo del tabaco! [...] Digo vale, vale, yo lo hago así como quiere, estoy cuidando mucho... no quiero molestarle. Y si mis clientes se ponen un poco ruidosos pues digo: o entráis dentro o ya terminamos la fiesta. Yo prefiero cerrar la terraza [...] Yo no digo que mis clientes no molestan, puede ser que molesten, pero yo estoy cuidando mucho”. 
Este tipo de situaciones conflictivas no son nuevas, sino que son habituales en torno a la actividad hostelera, por esa colisión de intereses entre comerciantes y vecinos, independientemente de su origen nacional, como muestra otro ejemplo que nos relata en 2005 el dueño, español, de dos bares en el barrio de Las Peñuelas: con respecto a uno de los bares no "he molestado porque también tengo la ventaja de que el primer piso son unas oficinas, entonces a las 20 hrs. cierran, así que al segundo piso ya no le molestas". Con respecto al otro bar explica que "hubo un pequeño problema porque estaban los techos muy altos y tuvieron que bajar los techos y en el primer piso sí hacía bastante ruido. Se fue dejando un poco y ya el señor se enfadó y tuvo que denunciarlo con razón. Se hizo la obra y perfectamente”.

Estos ejemplos nos muestran situaciones conflictivas, pero también mecanismos para gestionarlas ${ }^{19}$. El verdadero "problema" no es, por lo tanto, la situación conflictiva que suele conllevar este solapamiento de espacios, sino la forma de abordarla. En Gómez y Martínez (2012: 132) analizábamos dos casos de disputas entre vecinos y dueños de establecimientos de hostelería y comercio en torno a las molestias que provocan estos últimos, cuyo tratamiento fue muy distinto. Una vecina autóctona de Carabanchel se quejaba de la siguiente manera de establecimientos regentados por brasileños con motivo de las reuniones vinculadas al último mundial de fútbol en 2010: “Ustedes no saben qué es ciudadanía. Están aquí haciendo ruido toda la noche y nosotros que somos gente seria tenemos que trabajar mañana"20. La respuesta de las autoridades ante las quejas de los vecinos fue redadas de la policía pidiendo papeles y deteniendo a inmigrantes irregulares. Con respecto a un caso similar, pero continuado en el tiempo, una vecina española de origen argentino se quejaba en 2012 de establecimientos regentados por españoles en el centro de Madrid: "Y el fútbol [...] los bares tienen enormes pantallas con forofos de todos los colores, porque a distintos horarios van jugando los distintos equipos, con lo cual en esta época [primavera] empezamos a no poder dormir. Y si comentas con algún comerciante, te ven como si estuvieras loco. Es hostil”. En este caso, las actuaciones fueron poco resolutivas, a pesar de que las quejas vecinales eran las mismas que en el caso de Carabanchel ${ }^{21}$.

Aramburu (2000: 159) describe y compara dos casos similares en Barcelona, donde también la gestión y el desarrollo del conflicto fueron diferentes en función de la presencia o no de inmigrantes como actores de la situación conflictiva. Una de las situaciones tenía lugar en la zona de Correos donde jóvenes estudiantes autóctonos iban a divertirse a los locales de la zona los fines de semana, armando escándalo, ensuciando las calles y molestando a la población mayoritariamente mayor, también autóctona, residente allí. El otro caso se situaba en la calle Carders y era protagonizado por población autóctona de edad avanzada y residente en la zona y vecinas dominicanas jóvenes, residentes (o con negocios) que los fines de semana ocupaban las calles, ponían música alta, etc. alterando el descanso de las personas mayores. Pero una problemática tan parecida tuvo un tratamiento muy distinto: "Mientras que el conflicto de la zona de Correos se 
veía como un conflicto intergeneracional en torno al uso de espacios públicos, el de la calle Carders se veía como un conflicto intercultural que hundía sus raíces en la concepción y el uso de la calle propios de la cultura dominicana, diferente de la de aquí”.

En esto se aprecia también la importancia de otro actor en este tipo de conflictos: las autoridades y las instituciones públicas pues, como recoge Cachón (2008a: 443) pueden condicionar la gestión de los conflictos, acelerarlos o agravarlos en función de la interpretación que hagan de "las causas de los mismos y la falta de reacción o una acción insuficiente (o mal orientada) en los primeros pasos del conflicto". No podemos olvidar además que estas autoridades forman parte de la sociedad receptora que ejerce su hegemonía, en este caso a través del poder político y administrativo ${ }^{22}$.

\section{Comercio de barrio y oportunidades múltiples de relación interétnica}

El tercer planteamiento sobre el que se ha trabajado es que los vecinos de cualquier barrio se mueven y relacionan en múltiples ámbitos y espacios donde interactúan con personas de distintos orígenes ${ }^{23}$. En este sentido, los establecimientos comerciales asociados a colectivos determinados no constituyen el único espacio comercial donde se mueven tanto autóctonos como inmigrantes. La información cualitativa en la que se basa este artículo, así como los estudios sobre hábitos de compra y consumo a los que ya me he referido muestran con claridad: 1) que las personas inmigrantes realizan la mayor parte de su abastecimiento en los mismos lugares que la población autóctona (supermercados y mercados de barrio), lo cual garantiza una interacción, por de muy baja intensidad que sea, entre unos y otros; 2) supermercados, pequeño comercio, bares y restaurantes regentados por españoles han incorporado a sus plantillas a personal de origen extranjero que interactúan con la clientela española; 3) muchos de los establecimientos que regentan las personas de origen extranjero no están dirigidas a su colectivo de origen, sino que tienen un carácter generalista o, incluso, orientado específicamente al grueso de la población autóctona, contribuyendo así a la recreación identitaria de ésta. Es el caso de las fruterías — negocio en alza en los últimos años por el bajo coste de inversión vinculado a la rápida rotación del género- donde vemos comprar a gente de múltiples orígenes; por ejemplo, en el barrio madrileño de Lavapiés, en la calle Tribulete, se ubican muchos de estos negocios donde compran e interactúan con sus dependientes (pakistaníes, bangladeshíes, sobre todo) no sólo connacionales, sino también vecinos españoles, ecuatorianos, marroquíes, chinos, etc. Por otra parte, la mayoría de los establecimientos regentados por comerciantes chinos en los barrios de Madrid corresponden a bazares o tiendas de alimentación que frecuentan personas de todos los orígenes e, incluso, en ellas, encontramos de manera explícita ejemplos de expresión identitaria de los autóctonos. En el mes de mayo de 2013, próxima la celebración de la fiesta dedicada a San Isidro, patrón de Madrid, podemos ver 
en el bazar “La casa de Pin”, ubicado en uno de los márgenes del barrio de Lavapiés, un escaparate con cuatro maniquíes, una pareja de adultos y otra de niños, ataviados con los rajes de “chulapos”, típicos de Madrid.

Tiendas, bares, restaurantes, peluquerías, etc. son lugares donde interaccionan los vecinos del barrio, ya sea en su papel de comerciantes o de clientes. Estos establecimientos son espacios “donde se encuentran personas que ya se conocen, ayudando a mantener y consolidar esos lazos ya existentes y personas que no se conocían pero, a través del encuentro continuado, acaban estableciendo algún tipo de lazo social” (Gómez Crespo 1994: 414). Sea cual sea el grado de intensidad de esos lazos, es un espacio para el encuentro entre vecinos, no sólo dentro de los establecimientos, sino también en las rutas de paso que configuran ${ }^{24}$.

Por ejemplo, en el trabajo de campo realizado en 1991 (Gómez Crespo 1994: 415) en una ferretería del barrio madrileño de Las Peñuelas, se podía observar el "trasiego de personas que entran y salen, compran y charlan o incluso gente que únicamente entra para echar una parrafada y saludar al dueño y los dependientes”, conversando sobre fútbol, política, economía o inseguridad ciudadana. En 2005, 14 años después, en este mismo establecimiento quienes lo regentan decían: “en vez de Ferretería Isidro podríamos poner aquí entra y cuéntanos tu vida, porque todo el mundo nos la cuenta”. Y en este momento, quienes contaban sus vidas ya no eran sólo los vecinos españoles “de toda la vida”, sino también nuevos vecinos de origen extranjero (entre el $40 \%$ y el 60 \% de su clientela, según sus estimaciones) pues, como decía el dueño, en tono cordial, “esta gente latina habla mucho".

En una panadería regentada por ecuatorianos en el barrio de Vista Alegre en el distrito de Carabanchel, una dependienta explica ${ }^{25}$ : "Entran a comprar latinoamericanos, pero también entran españoles. Al principio a los españoles les cuesta decidirse, se quedan un buen rato mirando, hasta que les das a probar alguna cosa y ya se deciden. Y luego vienen seguido a comprar. También vienen sobre todo gente de Ecuador, de Colombia... porque ya conocen lo que vendemos aquí, y porque están acostumbrados a estos productos”.

Y en boca de la dueña del bar de Almenara que tan mala imagen tiene de los extranjeros encontramos el relato de hechos que no coinciden con su discurso: "tengo una amiga dominicana, que es un encanto de mujer. Es verdad, que no me acordaba. Una bellísima persona, trabajadora. Tiene una peluquería aquí, y es un encanto de mujer. Ella viene, me llama, se va a su país y me llama, viene a vernos, nos da un beso, y es un encanto. Y su hija igual, y es dominicana. No me acordaba. La conozco desde hace tres años que puso la peluquería aquí y es muy maja, claro, y somos amigas. Una chica correcta, maja, trabajadora. Se sabe comportar muy bien, muy bien, muy bien. También te digo que ella no es de los que han venido ahora, ella lleva aquí muchos años...”. Por otra parte, emplea a una camarera, con la que tiene una buena relación, que es de origen marroquí. 
También en Almenara, un vecino dominicano comenta sobre un comerciante marroquí: "en este barrio, en términos de convivencia, tengo la suerte con el marroquí que puso su tienda, y me deja muchas veces llevar las cosas, y se lo pago después, cuando tengo dinero y lo hace con toda la gente. Y a veces te deja las cosas a precios muy bajos. Este señor está haciendo un trabajo grande, es la fuente de los inmigrantes, van todos los inmigrantes a comprar allí.”

O un comerciante rumano que explicaba en 2001 en Coslada: "Pues por la mañana, mayoría son la gente del barrio, porque es una tienda que lleva ya 20 años aquí [cogida en traspaso a un español], y la gente está acostumbrada, ¡ay! se me ha olvidado aceite o azúcar y voy, luego el pan, que traigo un pan bueno y la gente le gusta comprarlo aquí, y luego por la tarde, sobre todo los domingos, los fines de semana, pues me visitan los rumanos que vienen de toda la parte de Madrid a comprar esta sémola o el queso que también lo tengo típico de allí [de Rumania].” "Pues hay mucha gente, considero que nos odian, pero a través de las clientas buenas, poco a poco se han ido, yo que sé, han ido viniendo gente nueva y una vez que entraban porque les hacia falta algo, ya cambiaba de opinión, y empezaban a venir, ha sido bastante duro.”

En estos contextos migratorios, esta funcionalidad de los comercios como terreno para el encuentro implica que son lugares para la interacción entre personas de distintos orígenes nacionales y etnoculturales. Más allá de la idea de comercios dirigidos a colectivos nacionales y étnicos determinados en los que sólo se dan relaciones intragrupales, los hechos nos muestran un campo donde la interacción entre personas de distintos grupos es la tónica cotidiana, pues no debemos olvidar la presencia cada vez más habitual de trabajadores inmigrantes en comercio y hostelería regentada por autóctonos, de cara al público y, por lo tanto, protagonizando este tipo de interacciones; además de los establecimientos comerciales que incorporan todo tipo de productos y servicios, al gusto de distintos colectivos (incluido el español) por los que transita y, por lo tanto, interaccionan vecinos de distintos orígenes.

En conclusión, y retomando los principios en los que se asienta el enfoque interculturalista, se pueden enfatizar varios puntos relevantes para avanzar en la incorporación del espacio comercial como clave para una intervención comunitaria que persigue la promoción de la convivencia y la cohesión social en contextos de migración.

En lo que respecta a los principios de igualdad y no discriminación etnorracial, y de respeto y derecho a la diferencia etnocultural, el análisis presentado muestra la necesidad de no estigmatizar la expresión identitaria que se da en los establecimientos comerciales que surgen en torno a los distintos colectivos de inmigrantes, pues cumplen exactamente la misma función sociocultural que en el caso de los autóctonos. Por otra parte, la incidencia negativa sobre la convivencia que se atribuye a algunos de ellos (como los locutorios y los bares), en realidad, remiten a situaciones con- 
flictivas que se producen por la colisión de intereses y normas propios de espacios que se solapan. La solución a los ejemplos que hemos recogido no pasa por que la vecina de la zona centro de Madrid se marche a vivir a otro lugar como le sugería el dueño de local que la impedía dormir, ni porque Nina se lleve a otro sitio su bar, sino por buscar acuerdos y consensos a partir de un análisis no prejuicioso del conflicto que parte del respeto mutuo.

En cuanto al principio de interacción positiva y, en vinculación con lo anterior, los casos recogidos muestran que la imagen de "guetización" de la población inmigrante en torno a espacios comerciales propios no se ajusta a la realidad, sino que las interacciones entre las personas de distintos orígenes se suceden en múltiples espacios, entre ellos el comercial. Frente a las visiones negativas de autoridades, técnicos y vecinos, la convivencia se abre paso en torno al espacio comercial, más allá de la contundencia de los prejuicios y discursos del rechazo, lo cual abre oportunidades para una intervención comunitaria participativa y eficaz. 


\section{Notas}

${ }^{1}$ Aprobado a finales de 2011, antes de las últimas elecciones generales que trajeron un cambio de gobierno.

${ }^{2}$ En el municipio de Madrid desapareció después de 12 años de funcionamiento ejemplar el Servicio de Mediación Social Intercultural, que fue sustituido por un Servicio de Dinamización de Espacios Públicos que apenas si ha durado tres años.

${ }^{3}$ Comunidad entendida en el sentido que le da Ander-Egg (1980: 44-45) como "agrupación organizada de personas que se perciben como una unidad social [...]. Cuyos miembros participan de algún rasgo, interés, elemento, objetivo o función común [...], con conciencia de pertenencia [...], situados en una determinada área geográfica [...] en la cual la pluralidad de personas interacciona más intensamente entre sí que en otro contexto”.

${ }^{4}$ Desde hace tres años el IMEDES coordina el Proyecto de Intervención Comunitaria Intercultural (Proyecto ICI) que Obra Social "la Caixa” impulsa en 17 territorios del estado español, donde desde una metodología participativa se viene trabajando en el desarrollo comunitario y la promoción de la convivencia intercultural.

${ }^{5}$ Por ejemplo, en el Proyecto ICI ya mencionado, en algunos territorios como el ubicado en Logroño, se vienen desarrollando actuaciones específicas en torno al ámbito comercial; Zegri, Navarro y Aramburu (2009) presentan también una experiencia de gestión de la diversidad en este ámbito.

${ }^{6}$ Este papel social y cultural del comercio no es nuevo, sino algo que ha acompañado a la actividad del intercambio comercial siempre y en todos los países y regiones del mundo (Gómez Crespo 1993); por lo tanto, el análisis que se ha realizado parte de esta funcionalidad social y cultural y, dentro de ella, se analiza lo que acontece cuando el contexto local se caracteriza por una diversidad sociocultural significativa fruto de la migración.

${ }^{7}$ Proyecto dirigido entre 2010 y 2013 por Carlos Giménez, catedrático de Antropología Social de la Universidad Autónoma de Madrid (UAM) en el seno del Instituto de Migraciones, Etnicidad y Desarrollo Social (IMEDES, www.uam.es/imedes). El equipo de esta investigación, enmarcada en el Programa Nacional de Proyectos de Investigación Fundamental, del VI Plan Nacional de Investigación Científica, Desarrollo e Innovación Tecnológica 2008-2011, se completa con Joaquín Eguren (Universidad Pontificia Comillas), Menara Lube (Centro de Investigaciones del Hombre en el Desierto, Universidad de Tarapacá, Chile), Carlos Peláez (Universidad Complutense de Madrid), Juan Ignacio Robles, Liliana Suárez, Ma Adoración Martínez y la autora de este artículo, de la UAM.

${ }^{8}$ Fragmentos de la entrevista realizada por los alumnos Eduardo Tchipolo e Ivonne Herrera del Practicum de la Licenciatura en Antropología Social y Cultural (curso 2011-2012) de la Universidad Autónoma de Madrid, dentro de las actividades de investigación del Proyecto I+D sobre conflictividad y migración en contextos locales, tutorizadas por $\mathrm{M}^{\mathrm{a}}$ Adoración Martínez Aranda y la autora de este artículo.

${ }^{9}$ Fragmento de entrevista realizada por la autora al representante de una confederación de asociaciones de comerciantes de Madrid, dentro del Estudio sobre el Estado de la Convivencia llevado a cabo en el Observatorio de las Migraciones y la Convivencia Intercultural de la Ciudad de Madrid en 2005. Fruto de este estudio es la obra de Gómez Crespo 2007. 


\begin{abstract}
${ }^{10}$ Por ejemplo, el estudio de la consultora A C Nielsen (2003), la encuesta del OMCI (2005) sobre la contribución de la población inmigrante a la economía de Madrid o los datos contenidos en el Anuario de la Convivencia Intercultural de la Ciudad de Madrid (OMCI 2006), donde se especifica que en torno al $90 \%$ de los inmigrantes de origen extranjero acude a supermercados, mercados y comercios regentados por españoles, y cerca del $70 \%$ frecuenta bares también españoles.
\end{abstract}

${ }^{11}$ Garcés (2010: 200) aborda la apertura de establecimientos comerciales dirigidos a la población inmigrante peruana en Chile señalando no sólo su carácter "como locus de recursos para la reproducción del colectivo migrante, como espacios identitarios y soportes de un campo transnacional", sino también "como espacios denotados o estigmatizados por parte o desde diversos agentes individuales o institucionales de la sociedad chilena".

${ }^{12}$ Estudio sobre el Estado de la Convivencia en la Ciudad de Madrid 2005.

${ }^{13}$ Tanto los bares españoles a los que se refiere el vecino entrevistado como los bares de los inmigrantes hacen lo mismo: contribuir a la expresión identitaria a través de uno elemento cultural esencial para ello como es la alimentación como recoge Contreras (1993: 66), "Dado el significado simbólico de los alimentos, resulta fácil, pues, identificar a las personas según lo que comen, del mismo modo que ellas se identifican o se construyen mediante la comida [...]. Mediante determinados usos y preferencias alimentarias, un individuo se identifica con un determinado grupo social, étnico o de edad”.

${ }^{14}$ Esta incorporación de productos se va produciendo poco a poco en algunos mercados, supermercados, en algún bar y restaurante, pero son muchos los bares "típicamente” españoles donde no es así, aunque sus camareros o personal de cocina provengan de otros países. Por ejemplo, el bar de Almenara mencionado cuenta con una camarera de origen marroquí.

${ }^{15}$ Este proceso se aborda en Gómez 2007.

${ }^{16}$ Estudio realizado en el Programa Migración y Multiculturalidad de la Universidad Autónoma de Madrid.

${ }^{17}$ Esta culturalización o etnización del conflicto es un fenómeno que se repite en los contextos locales de migración; por ejemplo, Séguin (1997: 395) aborda las relaciones interétnicas en las comunidades de vecinos y señala que "Dans leur discours sur les tensions et les conflits, les locataires ont le plus souvent tendance à ethniciser les problèmes de cohabitation, c'est-à-dire à étendre des comportements jugés dérangeants observés chez un ou deux résidants d'un groupe ethnique ou racial à l'ensemble du groupe”.

${ }^{18}$ Entrevista realizada por la autora dentro del estudio Inmigración y mercado de trabajo en el municipio de Madrid: actores, estrategias y desafíos para la integración, dirigido por el profesor Carlos Giménez Romero e integrado en las acciones del proyecto "Dotación de instrumentos de intervención para la inserción laboral de inmigrantes y refugiados: análisis de la realidad y formación de profesionales en mediación laboral” (2003, Fundación Luis Vives-Fondo Social Europeo-Fundación General de la Universidad Autónoma de Madrid).

${ }^{19}$ Nótese que, en el caso de Nina, según su relato, no hay una comunicación previa por parte de los vecinos para mostrarle su malestar, sino una llamada directa a la policía; mientras 
que en el caso del bar de Las Peñuelas, los vecinos habían hablado con el dueño y sólo pusieron la denuncia cuando este hizo caso omiso de las quejas, como él mismo reconoce.

${ }^{20}$ Agradezco a Menara Lube que me haya prestado este ejemplo extraído de su diario de campo de junio de 2010.

${ }^{21}$ Conviene señalar que la poca diligencia en resolver la situación por parte de la administración municipal no se debe al origen nacional de la mujer entrevistada, puesto que las quejas que ella expresaba son comunes al conjunto de los vecinos de la zona, en buena medida, autóctonos, sino más bien a los intereses económicos de los negocios que pueblan los locales comerciales del barrio orientados a los turistas.

${ }^{22}$ Garcés (2010: 275, 279) también habla, en el caso de Chile, del poder institucional que criminaliza el espacio donde se concentran los comercios peruanos, las redadas en busca de inmigrantes irregulares y el "hostigamiento de que suelen sentirse víctimas los comerciantes peruanos por parte de los funcionarios”.

${ }^{23}$ Se puede hacer extensivo al espacio comercial lo que señala Torres (2005: 39) con respecto a las reuniones por parte de ecuatorianos en parques y que tienden a interpretarse como poca voluntad de integración: "no parece incompatible la existencia de espacios comunes, compartidos con el resto de vecinos, y de espacios más o menos propios. Unos y otros no responden a una diferente voluntad de inserción. Más bien, constituyen formas distintas de cubrir una diversidad de necesidades de sociabilidad”.

${ }^{24}$ Torres (2008: 376) enfatiza también el papel que está desempeñando el ámbito comercial para la incorporación de la población inmigrante a la vida vecinal. En el caso del barrio valenciano de Russafa explica: "La presencia de los ecuatorianos en el Mercado supone una interacción cotidiana, banal pero satisfactoria para todos los actores que contribuye a incluir a los latinoamericanos como unos clientes y vecinos más”.

${ }^{25}$ Extracto de la entrevista realizada por las alumnas Marta Larreina y Ana Rodríguez del Practicum de la Licenciatura en Antropología Social y Cultural (curso 2011-2012) de la Universidad Autónoma de Madrid dentro de las actividades de investigación del Proyecto I+D sobre conflictividad y migración en contextos locales, tutorizadas por Ma Adoración Martínez Aranda y la autora de este artículo. 


\section{Bibliografía}

AC Nielsen (2003), Los hábitos alimentarios de los inmigrantes en España, Dirección General de Industria Agroalimentaria y Alimentación. Ministerio de Agricultura, Pesca y Alimentación, Madrid.

Ander-Egg, E. (1980) Metodología y práctica del desarrollo de la comunidad, Ed. El Ateneo. Barcelona.

Aramburu, M. (2000), Bajo el signo del gueto. Imágenes del Inmigrante en Ciutat Vella, Tesis Doctoral. Departamento de Antropología Social, Universidad Autónoma de Barcelona.

Contreras, J. (1993), Antropología de la Alimentación, Eudema, Madrid.

Garcés, A. (2010), Movimientos y localizaciones: espacios públcios y economías de la migración peruana en santiago de Chile, Tesis Doctoral. Dpto. de Antropología Social y Pensamiento Filosófico Español, Universidad Autónoma de Madrid.

Giménez, C. (2002) “Planteamiento multifactorial para la mediación e intervención en contextos multiculturales. Una propuesta metodológica de superación del culturalismo”, en F. J. García Castaño y C. Muriel (eds) La inmigración en España: contextos y alternativas. Laboratorio de Estudios Interculturales. Universidad de Granada.

Ídem (2005), “Convivencia: conceptualización y sugerencias para la praxis”, en Puntos de Vista, $n^{\circ}$, págs. 7-31.

Ídem (2009a), “Aplicaciones del enfoque interculturalista: Políticas públicas, escuela, mediación, barrios y civismo”, en Veiga Simao, A. M., Caetano, A. P. Y Freire, I. (eds.) Tutoria e Mediaçao em educaçao. Educa e autores, Lisboa.

Ídem (2009b) "Parte II. El impulso de la convivencia ciudadana e intercultural en los barrios europeos: marco conceptual y metodológico”, en Marco conceptual y buenas prácticas en ciudadanía y convivencia en barrios europeos, págs. 103-139. INTI-CIEN. Serie Igualdad y Ciudadanía, 13. Diputació de Barcelona, Barcelona.

Gómez Crespo, P. (1993), Comprar y vender. La cultura del comercio y el mercado, Eudema, Madrid.

Ídem (1994), El papel y económico y social del pequeño comercio: un modelo de análisis, Tesis doctoral, Universidad Autónoma de Madrid.

Ídem (2007), Inmigración y comercio en Madrid: empresarios, consumidores, trabajadores y vecinos, OMCI, Ayuntamiento de Madrid. 
Gómez Crespo, P. y Martínez Aranda, M. A. (2012), “Convivencia y conflicto en contextos locales de inmigración: articulación de espacios de sociabilidad en los barrios madrileños”, en Revista de Ciencias Sociales UNAP, (Monográfico Alteridades Desbordadas), $n^{\circ}$ 28, págs. 121-144.

Ídem (2013), “Convivencia y espacios de construcción de "lo latino” en los barrios de Madrid”, en $7^{\circ}$ Congreso del Consejo Europeo de Investigaciones Sociales de América Latina "Memoria, Presente, Porvenir". Simposio: "Desplazar, reconstruir y narrar América Latina:Memorias, imaginarios y prácticas a partir de la experiencia migratoria”, CEISAL/Universidad Fernando Pessoa/ Núcleo de Estudios Latinoamericanos, Oporto.

Martínez Aranda, M. A. y Gómez Crespo, P. (2012), “Recreación identitaria en espacios públicos: convivencia y conflicto en contextos locales de inmigración”, en Actas del Tercer Congreso Latinoamericano de Antropología ALA 2012. ISBN 978-956-19-0779-9.

Monnet, J. (1996) "Espacio público, comercio y urbanidad en Francia, México y estados Unidos”, en Alteridades, vol. 6, $n^{\circ}$ 11, págs. 11-25.

OMCI (2005), Cuestiones claves de la contribución de la población inmigrante a la economía de Madrid. Encuesta del Instituto de Predicción Económica L. R. Klein - Centro Gauss, del Departamento de Economía aplicada de la Facultad de Ciencias Económicas y Empresariales de la Universidad Autónoma de Madrid.

Ídem (2006), Anuario de la Convivencia Intercultural de la Ciudad de Madrid 2006, Ayuntamiento de Madrid.

Torres, F. (2005), "Los espacios públicos en la ciudad multicultural: reflexiones sobre dos parques en Valencia”, en Puntos de Vista, $n^{\circ} 1$, págs. 33-49.

Ídem (2008), “Los nuevos vecinos en la plaza, inmigrantes, espacios y sociabilidad pública”. AIBR, Revista de Antropología Iberoamericana, año/ vol 3, nº 3, págs. 366-397.

Zegri, M., Navarro, J. M. y Aramburu, M. (2009), “Gestión de la Diversidad entre Pequeños Comercios de Barcelona. Análisis de una Experiencia de Mediación Comunitaria Intercultural”, en Intervención Psicosocial, Vol. $18, n .^{\circ} 1$, págs. $37-45$. 